\title{
THE CAPACITY LIMITS OF ROUNDABOUTS
}

According to the manuals for the capacity calculation and evaluation of roundabouts it is possible to calculate and evaluate the capacity of roundabout entries only under particular traffic conditions. However, it is not possible to simply determine the total capacity of roundabouts. For this reason, custom software tool, which allows total capacity calculation for different models of roundabouts under different traffic conditions, has been created. Results of the maximum capacity limits for some of the analyzed roundabouts at the most influencing traffic conditions settings are shown in the article. For better illustration, the results are compared with maximum capacity limits of simple unsignalized intersection.

Keywords: Roundabout, capacity, traffic load, critical gap.

\section{Introduction}

Modern roundabouts which were developed in the United Kingdom have started to be built in Slovakia after 1999. Concurrently, mainly in urban and rural areas, single-lane roundabouts are widely used. The reasons for their use are mostly:

- enhancement of safety in comparison with other forms of at-grade intersections;

- $\quad$ speed reduction, as one of significant reductions of fatal and injury accidents;

- noise reduction [1];

- aesthetic improvement; and

- higher traffic capacity in comparison with unsignalized intersections [2] and, in some cases, also with signalized intersections [3].

Higher traffic capacity of roundabouts in comparison with unsignalized intersections is related to several factors. One of them is that traffic operation at roundabouts is much easier than traffic operation at unsignalized intersections. At roundabouts, vehicles travel clockwise around a raised centre island, with entering traffic yielding the right-of-way to circulating traffic. This fact results not only in reduction of conflicting points in comparison with unsignalized intersections - from 32 conflicting points at four leg unsignalized intersections to 8 conflicting points at single-lane roundabouts. Moreover, it results in reduction of the number of conflicting traffic streams and hierarchical levels of priorities - from 4 to 2 ranks. Further important factor is the low speed of conflicting traffic flows at the circulating lane - usually $20-25 \mathrm{~km} / \mathrm{h}$ [4]. At lower speeds of conflicting traffic flows, the critical gaps and follow-up headways are lower, which means more acceptable gaps for safe entrance of vehicles to the circulating lane and also higher capacity.

The aim of the article is to present the capacity limits for selected types of roundabouts under the most influencing traffic conditions settings - proportion of left-turning vehicles and ratio of traffic volume on the major and minor streets. For better illustration they are compared with capacity limits of simple unsignalized intersection - intersection with shared lanes on all legs.

\section{Types of roundabouts in Slovakia}

Concurrently, mainly compact small single-lane roundabouts are built in Slovakia. They are roundabouts with diameter between $26 \mathrm{~m}$ and $40 \mathrm{~m}$ and with single-lane entry at all legs, and one circulating lane (Fig. 1).

Under larger traffic volume large double-lane roundabouts with diameter more than $40 \mathrm{~m}$ (usually up to $60 \mathrm{~m}$ ) are built. These roundabouts are designed with single- or double-lane entries and two circulating lanes. They are built occasionally because of lower safety on the circulating lane when vehicles need to weave [5]. For the same reason, capacity of the internal lane at double-lanes entries is not much efficient [6 and 7].

Due to deficiency of free space in urban area mini-roundabouts with diameter between $14 \mathrm{~m}$ and $22 \mathrm{~m}$ and with traversable island for larger vehicles are built (Fig. 1).

In recent years, turbo-roundabouts with the spiral arrangement of the circulating lane are designed and built in some European countries. Due to absence of standards and regulations to support

\footnotetext{
* Andrea Kocianova

Department of Highway Engineering, Faculty of Civil Engineering, University of Zilina, Slovakia

E-mail: andrea.kocianova@fstav.uniza.sk
} 
this type of roundabouts, they are not built in Slovakia, but it is only a question of a short time until this trend changes.
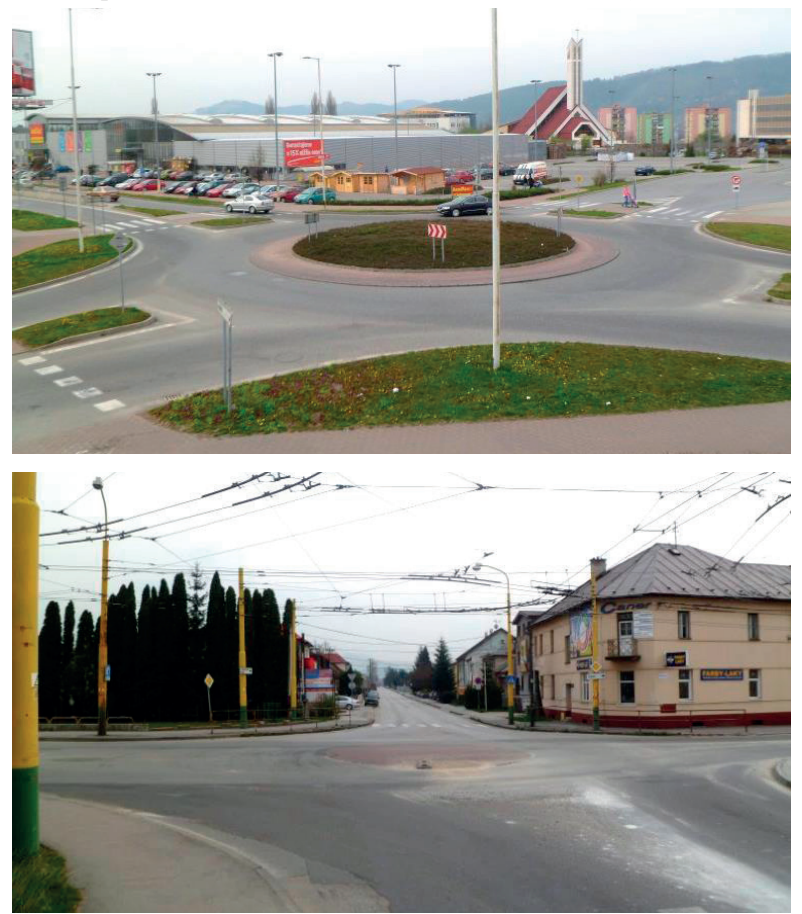

Fig. 1 Typical Slovak single-lane roundabout (up) and mini-roundabout (down)

\section{Capacity calculation of roundabouts}

Capacity manuals are used for capacity calculation but only the capacity of the roundabout entries under particular traffic conditions is possible to calculate and evaluate. However, the total capacity of roundabout as the maximum hourly rate at which vehicles can enter a roundabout under specific geometric and traffic conditions is required. For this reason, the custom software tool was created. By using this software tool the total capacity of various models of roundabouts under various combinations of traffic loads can be calculated in an iteractive fashion. It is possible to determine the maximum total capacity of roundabouts when the degree of saturation of any entry is equal to 1.0 - the reserve of capacity, as a difference between the entry capacity and entry traffic volume, is zero. In addition, it is possible to determine the total capacity of roundabouts for other levels of service. These levels of service depend on an average waiting time. The total capacity of roundabout, as the sum of traffic volumes on all entries of the roundabout, is reached if required limit of any entry is achieved.

As the basis for capacity calculation, the procedure in Czech capacity manual TP 234 [8] was used. Calculation method described in this manual is related to gap acceptance procedure. For the calculation of basic capacity of roundabout entry equation designed by $\mathrm{Wu}[9]$ is used (modified the basic idea of Tanner, 1962):

$G=3600 \cdot\left(1-\frac{t_{\min } \cdot q_{k}}{3600 \cdot n_{c}}\right)^{n_{c}} \cdot \frac{n_{e}}{t_{f}} \cdot e^{-\frac{q_{k}}{3600} \cdot\left(t_{c}-\frac{t_{f}}{2}-t_{\min }\right)}$

where:

$G$ - basic capacity of a roundabout entry [pcu/h],

$q_{k}$ - circulating traffic flow in front of the entry $[\mathrm{pcu} / \mathrm{h}]$,

$n_{c}-$ the number of circulating lanes [-],

$n_{e}$ - parameter taking into account the number of entry lanes [-],

$n_{e}=1.0$ for single-lane entry; $n_{e}=1.5$ for double-lane entry,

$t_{c}$ - critical gap [s],

$t_{f}$ - follow-up headway [s],

$t_{\text {min }}$ - minimum headway between the vehicles circulating in the circulating lane $[\mathrm{s}]$.

According to formula (1), the entry capacity of roundabout depends on circulating traffic flow, the number of circulating lanes, the number of entry lanes and on the driver gap acceptance behaviour. This driver gap acceptance behaviour is represented by the critical gap $t_{c}$, follow-up headway $t_{f}$ and minimum headway between circulating vehicles $t_{\min }$. Critical gap is the minimum gap between the vehicles on circulating lane which an entering driver is ready to accept to enter the roundabout. Follow-up headway is the time difference between two consecutive vehicles using the same gap to enter the roundabout.

The values of gap times $t_{c}, t_{f}$ and $t_{\min }$ specified in TP 234 were derived from experimental data on Czech roundabouts - Table 1. They depend on type and size of roundabouts. For single-lane roundabouts the gap times are also dependent on their geometry - distance between the exiting and entering conflicting points and entry radius. For capacity calculation, the Slovak capacity manual TP 10/2010 [10] has not been used. The reason is that the values of gap times have been taken from HBS (2001) and they are based on the initial experimental data on German roundabouts (observations of Stuwe, 1992). These values have not been verified under Slovak conditions and they are used regardless of the type and geometry of roundabouts (Table 1). Although the values of gap times in Germany have been updated [11], Czech parameters were used, because the traffic rules and a typical behaviour of drivers is very similar as Slovak and Czech Republic are neighbouring countries.

For minimum and maximum geometry parameters of singlelane roundabout, dependence of basic capacity of roundabout entry according to TP 234 is shown in Fig. 2. The chart also shows measurements of 5-minutes interval of saturation flows measured for several single-lane entries at roundabouts in Zilina (some of them are presented in [12]). In some cases, the measured capacity exceeds the value of the theoretical capacity according to TP 234 for minimum geometry parameters of roundabout (TP $234 \mathrm{~min}$ ), but only in a few cases, the measured maximum capacity is higher than theoretical capacity for maximum geometry parameters (TP 234 max). 
Values of gap times on roundabouts according to TP 234 and TP10/2010

Table 1

\begin{tabular}{|c|c|c|c|}
\hline TP 234 & $t_{c}[s]$ & $t_{f}[s]$ & $t_{\min }[s]$ \\
\hline Mini-roundabouts (Mini) & $t_{c}=4.5$ & $t_{f}=3.1$ & $\begin{array}{l}13 m \leq D \leq 23 m \\
t_{\text {min }}=3.45-0.05 \cdot D\end{array}$ \\
\hline Single-lane roundabouts $(1 / 1)$ & $\begin{array}{c}11 m \leq b \leq 20 m \\
t_{c}=5.6-0.1 \cdot b\end{array}$ & $\begin{array}{l}8 m \leq R \leq 16 m \\
t_{f}=3.6-0.0625 \cdot R\end{array}$ & 2.1 \\
\hline Double-lane roundabouts $(1 / 2,2 / 2)$ & 3.7 & 2.6 & 2.1 \\
\hline$T P 10 / 2010$ & $t_{c}[s]$ & $t_{f}[s]$ & $t_{\min }[s]$ \\
\hline Mini, 1/1, 1/2, 2/2 & 4.1 & 2.9 & 2.1 \\
\hline \multicolumn{4}{|c|}{$\begin{array}{l}D \text { - external diameter of roundabouts } \\
R \text { - entry radius } \\
b \text { - distance between the exiting and entering conflicting points }\end{array}$} \\
\hline
\end{tabular}
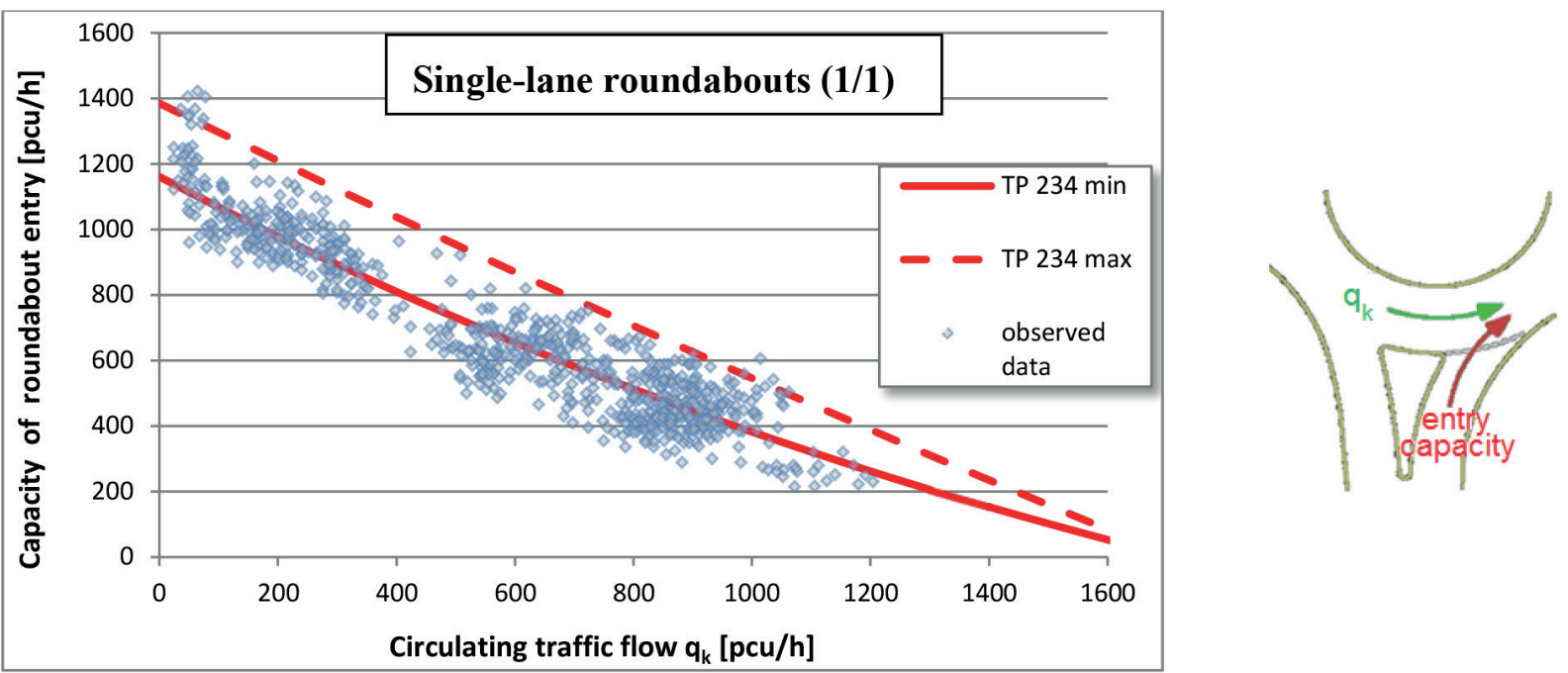

Fig. 2 Comparison of basic entry capacity of single-lane roundabouts according to TP 234 with measurements for single-lane roundabouts in Žilina

\section{Capacity limits of roundabouts}

Maximum capacity of roundabouts with various geometry parameters (type and size of roundabout, the number of entry lanes and circulating lanes) were evaluated within the analysis. Some of them were selected for the presentation of capacity results in the article. The analyzed roundabouts are listed in Table 2. Moreover, capacity limits of simple unsignalized intersection - with shared lanes on all legs - are also provided for comparison purposes.

In the calculation, it is considered that main and minor streets are crossed in the roundabout location. Two opposite roundabout entries at a major street are in the article referred to as the major entries and two opposite roundabout entries at a minor street are referred to as the minor entries.

Types of analyzed roundabouts - basic parameters

Table 2

\begin{tabular}{|c|c|c|c|c|}
\hline \multirow[b]{2}{*}{ Type of roundabout } & Mini-roundabouts & \multicolumn{2}{|c|}{ Small single-lane roundabouts } & Large double-lane roundabouts \\
\hline & $\begin{array}{l}\text { One lane on all entry, exit and } \\
\text { circulatory roadways }\end{array}$ & \multicolumn{2}{|c|}{$\begin{array}{c}\text { One lane on all entry, exit and circulatory } \\
\text { roadways }\end{array}$} & $\begin{array}{l}\text { Double-lane on all entry, exit and } \\
\text { circulatory roadways }\end{array}$ \\
\hline Labeling & Mini & $1 / 1 \min$ & $1 / 1 \max$ & $2 / 2$ \\
\hline$D$ & $14 \mathrm{~m}$ & \multicolumn{2}{|c|}{$26 m-40 m$} & $40 m-60 m$ \\
\hline$b$ & - & $11 \mathrm{~m}$ & $20 \mathrm{~m}$ & - \\
\hline$R$ & - & $8 \mathrm{~m}$ & $16 \mathrm{~m}$ & - \\
\hline
\end{tabular}


The results of the analysis have shown that proportion of traffic volume on the major street and proportion of left-turn vehicles (left-turn percentage) have a significant influence on the intersection capacity from the traffic conditions. For this reason, the following presented dependences are focused only on these two factors. In addition to the maximum total capacity of roundabouts, dependence of the minor entries capacity on the traffic volume on the major entries is shown.

Figure 3, for selected roundabouts and for simple unsignalized intersection, shows graphical dependencies of the minor entries capacity on the major entries traffic volume. The flow pattern is chosen as follows: proportion of left-turn vehicles and rightturn vehicles is $30 \%$ and $10 \%$ separately for all entries, a ratio of directions is the same on the major street and also on the minor street.

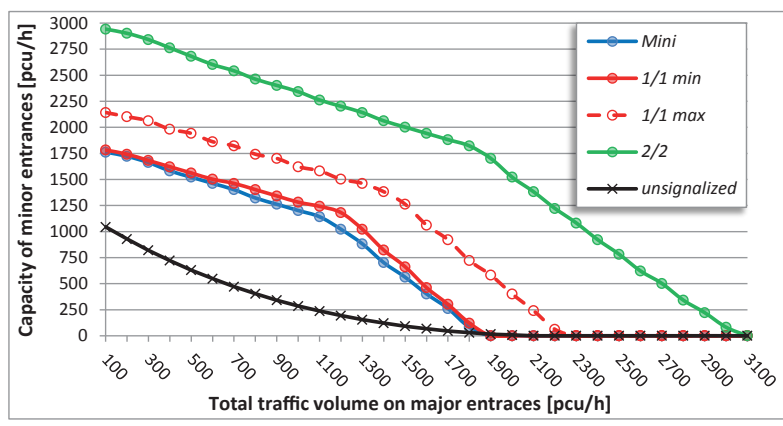

Fig. 3 Graphical dependence of the minor entries capacity on the major traffic volume

We can observe a significant decrease in the minor entries capacity depending on the increasing major entries traffic volume at all of intersections. Capacity of the single-lane roundabout with minimal parameters $(1 / 1 \mathrm{~min})$ is only slightly higher than capacity of the mini-roundabout (Mini). More significantly, the capacity increase can be achieved by single-lane roundabout with higher parameters $(1 / 1 \mathrm{max})$ - larger entry radius and wider splitter islands, which obviously assumes larger external diameter of roundabout. Higher traffic capacity can be achieved by large double-lane roundabout (2/2). However, it should be noted that they are less safe in comparison with single-lane roundabouts because of Slovak roundabout design method for this particular type of roundabout - vehicles must interweave on the circulating lane. All types of roundabouts achieve a significantly higher minor entries capacity in comparison with unsignalized intersection.

The chart in Fig. 3 also clarifies that the total capacity of all types of roundabouts rises when the traffic volumes of the all entries are closer to each other. The highest total capacity is not achieved at very high traffic volume on the major street, as it is for unsignalized intersection. The largest capacity of roundabouts is achieved in the point where the traffic volume at all entries to the roundabout is uniform.
On the charts shown in Figs. 4 and 5, we can observe influence of traffic volume proportion on the major entries (major entries percentage) and the left-turn percentage $(L)$ to the total capacity of roundabouts. While the total capacity of roundabouts is increased by reducing of proportion of the traffic volume on the major entries - about $15 \%-25 \%$ in dependence on left-turn percentage, conversely, the total capacity of unsignalized intersection is reduced to about $30 \%$.

Figure 4 shows the total capacity of single-lane roundabout with minimum parameters $(1 / 1 \mathrm{~min})$ which achieve about 1700 $\mathrm{pcu} / \mathrm{h}-2150 \mathrm{pcu} / \mathrm{h}$ at high traffic volumes on the major street - major entries percentage is $90 \%$. The total capacity of simple unsignalized intersection at the same flow pattern is about 1400 $\mathrm{pcu} / \mathrm{h}-1600 \mathrm{pcu} / \mathrm{h}$. If the traffic loads on the major and minor streets are uniform - major entries percentage is $50 \%$, the total capacity of $1 / 1 \mathrm{~min}$ roundabout is about $2200 \mathrm{pcu} / \mathrm{h}-2500 \mathrm{pcu} / \mathrm{h}$ and the total capacity of unsignalized intersection is only about $1000 \mathrm{pcu} / \mathrm{h}-1200 \mathrm{pcu} / \mathrm{h}$.

On this chart, the total capacity is shown for following flow pattern: $10 \%$ right-turn percentage and the same ratio of directions on the major and minor streets. At higher proportion of right-turn vehicles, the total capacity of roundabouts is increased. At different load ratio of directions on the major and minor streets, the total capacity is reduced.

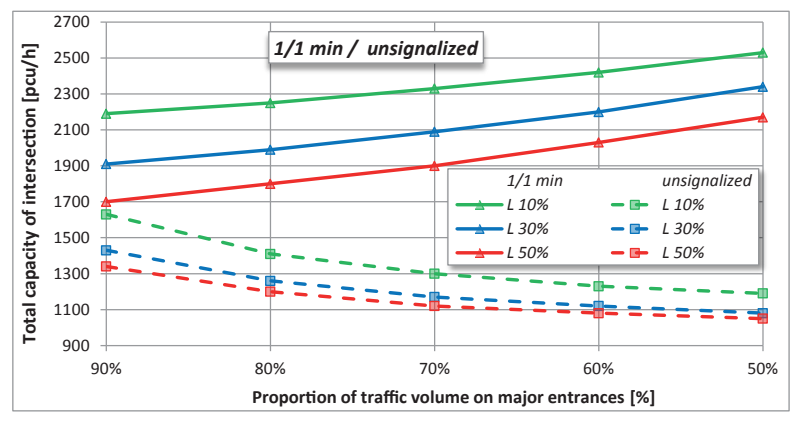

Fig. 4 Traffic volumes on major street influence the total capacity of single-lane roundabout and unsignalized intersection

Figure 5 shows an influence of left-turn percentage to the roundabouts capacity. Increase of left-turn percentage from $10 \%$ to $40 \%$ leads to a reduction of roundabout capacity by about $10 \%$ to $20 \%$ depending on traffic volume of the major entries. In higher traffic volumes of the major street the influence of left-turn percentage is more significant. For the given traffic conditions, the capacity were found at intervals: $1750 \mathrm{pcu} / \mathrm{h}-2400 \mathrm{pcu} / \mathrm{h}$ for the mini-roundabout, $1800 \mathrm{pcu} / \mathrm{h}-2500 \mathrm{pcu} / \mathrm{h}$ for single-lane roundabout with minimum parameters $(1 / 1 \mathrm{~min}), 2100 \mathrm{pcu} / \mathrm{h}$ - $3000 \mathrm{pcu} / \mathrm{h}$ for single-lane roundabout $1 / 1 \max , 2800 \mathrm{pcu} / \mathrm{h}$ $3900 \mathrm{pcu} / \mathrm{h}$ for double-lane roundabouts. Mini-roundabout thus can achieve capacity values of $30 \%-100 \%$ higher than capacity of simple unsignalized intersection. Single-lane roundabout with maximum parameters have $50 \%-150 \%$ higher traffic capacity 


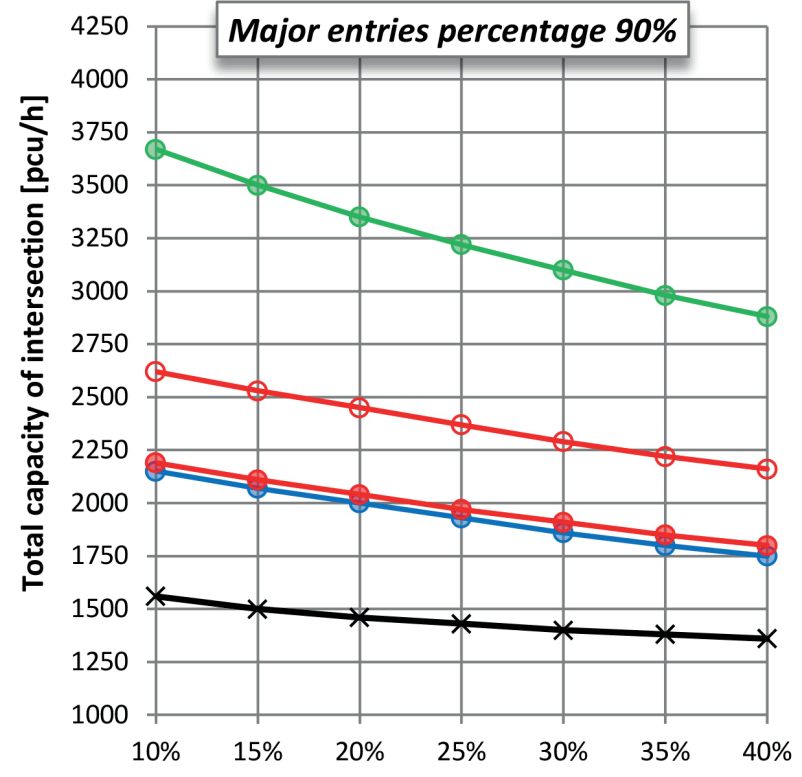

Left-turn percentage

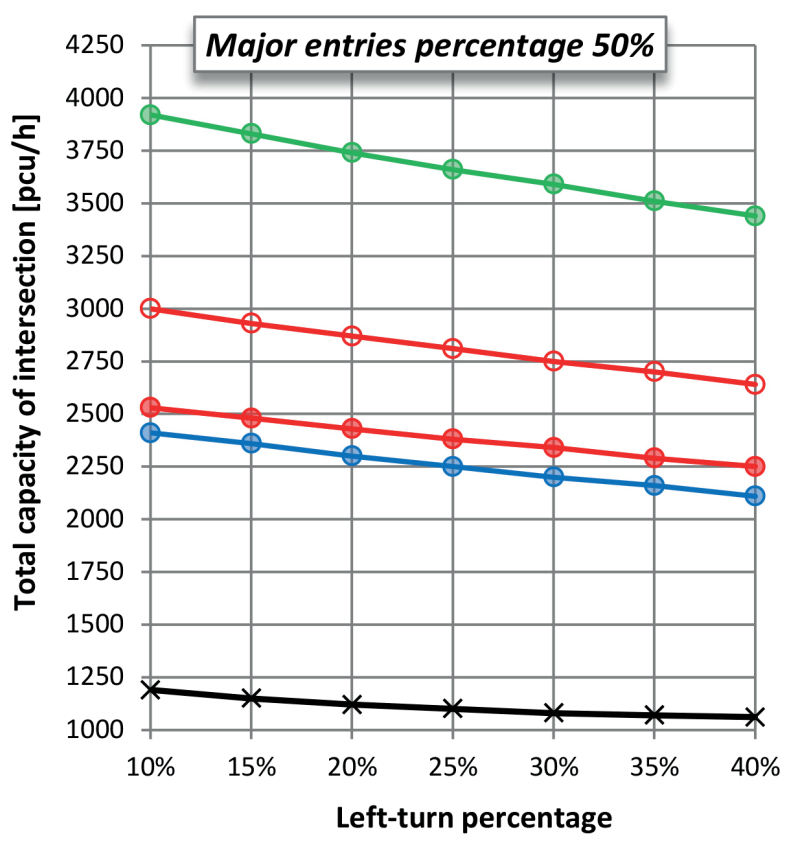

* unsignalized

Fig. 5 Total capacities of roundabouts and unsignalized intersection depending on proportion of left-turn vehicles

than simple unsignalized intersection, and large double-lane roundabout have the capacity even two or three times higher.

Maximum capacity limits for roundabouts and simple unsignalized intersection for the whole spectrum of observed combinations of traffic loads are shown in Fig. 6. The lower limit corresponds to the total capacity at unfavourable traffic conditions. When the maximum total traffic load of roundabout is less than this limit, roundabout will be always satisfactory. The upper limit indicates the maximum value of total capacity at favourable traffic conditions. When the maximum total traffic load of roundabout is greater than this limit, roundabout will be always unsatisfactory. Between these borders, it is necessary that the roundabout capacity is verified according to capacity regulations.

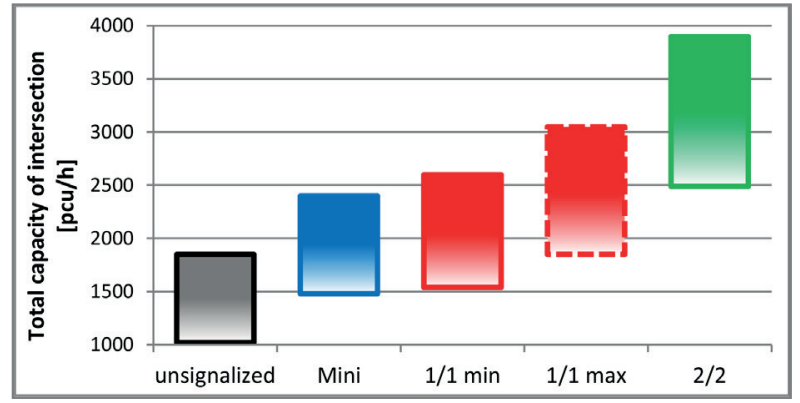

Fig. 6 Maximum capacity limits of roundabouts and simple unsignalized intersection
In Fig. 6, the maximum capacity limits for roundabouts are shown. These capacity levels can be reached, however, this will result in longer waiting times which will be around 100 to 150 seconds at the busiest roundabout entry. If we want to ensure a higher level of service, capacity limits of roundabouts will be lower. For example, level of service "D" - average waiting time at the busiest roundabout entry is equal to 45 seconds - this will be achieved at reduced maximum total capacity of roundabout, reduced by about $150 \mathrm{pcu} / \mathrm{h}$.

For comparison, following maximum traffic volumes during peak hours were measured at many overloaded intersections of two-lane roads in Zilina: in the range $1300 \mathrm{pcu} / \mathrm{h}-1600 \mathrm{pcu} / \mathrm{h}$ at simple unsignalized intersections; in the range $2200 \mathrm{pcu} / \mathrm{h}$ $2400 \mathrm{pcu} / \mathrm{h}$ at a mini-roundabout; in the range $2500 \mathrm{pcu} / \mathrm{h}-2700$ $\mathrm{pcu} / \mathrm{h}$ at single-lane roundabouts, and in the range $2000 \mathrm{pcu} / \mathrm{h}$ $2300 \mathrm{pcu} / \mathrm{h}$ at signalized simple intersections. These values do not necessarily mean a maximum total capacity of intersections.

\section{Conclusion}

Roundabouts are unsignalized intersections which can provide increased traffic safety as well as higher efficiency. Maximal capacity limits for different types of roundabouts, in different traffic conditions are presented in the article. The analysis showed a significant influence of traffic volume of the major street and proportion of left-turn vehicles to the total capacity of roundabouts. The influence of these factors can mean 
up to $40 \%$ difference in the total capacity of the same roundabout type. By suitable design of roundabouts significantly higher total capacity can be achieved in comparison with unsignalized intersections. Depending on roundabout geometry, and on traffic condition, maximum capacity limits for conventional single-lane roundabout can exceed simple unsignalized intersection capacity by $50 \%-150 \%$. Moreover, this will provide shorter waiting times on entries.

Presented maximum capacity limits of roundabouts can be exceeded. Additional efficiency can be achieved by addition of separate by-passes for right-turn vehicles, or by designing of modern roundabouts - turbo roundabouts - with spiral arranged circulating lanes, which are more efficient and also safer than conventional Slovak double-lane roundabouts.

\section{Acknowledgements}

This contribution/publication is the result of the project implementation:
Centre of excellence for systems and services of intelligent transport, ITMS 26220120028 supported by the Research \& Development Operational Programme funded by the ERDF.
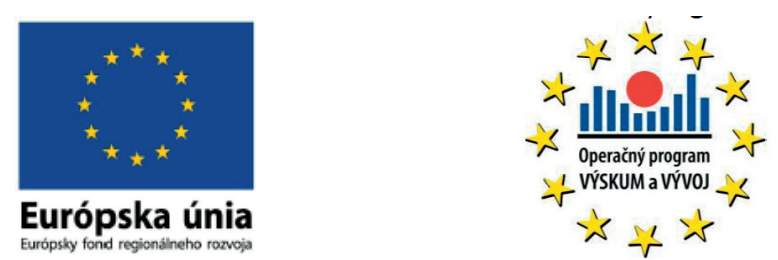

\section{Európska únia}

\section{Európsiy fond regionathehe rozvoja

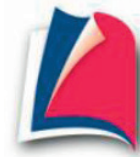 \\ Agentúra \\ Ministerstva školstva, vedy, výskumu a športu SR pre štrukturálne fondy EÚ}

„Podporujeme vyskumne aktivity na Slovensku/Projekt je spolufinancovany zo zdrojov EU“

\section{References}

[1] DECKY, M., TROJAnOVA, M., REMEK, L., JATY, L.: Noise Pollution from Roundabout Traffic in the outer Environment of Built-up Areas of Towns, $12^{\text {th }}$ Multidisciplinary scientific geoconference SGEM 2012, June, 2012, Albena, ISSN 1314-2704, pp. 927-934.

[2] SLABY, P., KOUKAL, M.: Capacity of At-grade Intersections in Relation to the Quality of Service (in Czech), Silnicni obzor, No. 9, pp. 234-238, 2005, ISSN 0322-7154 47320.

[3] Transport Research Board: Roundabouts: An Informational Guide. NCHRP Report 672 - $2^{\text {nd }}$ ed., Washington D.C., 2010.

[4] REZAC, M., CIHLAROVA, D., SEIDLER, T., SIMONIK, P.: Options to Mitigate Congestion on Roads, Proc. of Intern. Conference on Civil Engineering, Architecture and Building Materials, CEABM 2013. Jinan, May, 2013, vols. 361-363, pp. 2049-2052, ISSN 1660-9336, ISBN 978-3-03785-777-9.

[5] KRIVDA, V: Video-Analysis of Conflict Situations on Selected Roundabouts in the Czech Republic. Communications - Scientific Letters of the University of Zilina, vol. 13, No. 3, 2011, pp. 77-82, ISSN 1335-4205.

[6] BRILON, W.: Roundabouts: A State of the Art in Germany. National Roundabout Conference, Vail : Colorado, May, 2005

[7] SMELY, M., RADIMSKY, M., APELTAUER, T.: Capacity of Roundabouts with Multi-lane Entrances (in Czech), Dopravni inzenyrstvi, No. 1, pp. 20-21, 2011, ISSN 1801-8890.

[8] TP 234 Capacity Evaluation of Roundabouts (in Czech), EDIP, 2011, ISBN 978-80-87394-02-01.

[9] BRILON, W., BONDZIO, L., WU, N.: Unsignalized Intersections in Germany - a State of the Art, $2^{\text {nd }}$ Intern. Symposium for Unsignalized Intersections, Portland : Oregon, 1997.

[10] TP 10/2010 Capacity Calculation of Roads (in Slovak), MDPaT SR, 2010.

[11] BRILON, W.: Studies on Roundabouts in Germany: Lessons Learned, $3^{\text {rd }}$ Intern. TRB-roundabout Conference, Carmel : Indiana, May, 2011.

[12] GAVUlOVA, A., DRLICIAK, M.: Capacity Evaluation of Roundabouts in Slovakia. Transport and Telecommunication, vol. 13, No. 1, 2012, Riga, ISSN 1407-6160 (e-ISSN 1407-6179), pp.1-10. 